\title{
Our archetypal life functions
}

Volume 3 Issue 6 - 2015

\section{Opinion}

We are using the term archetype to refer to the inherent pattern, blueprint, or predisposition of the individual soul, the collective community soul, the universal life substance in which the individual and community life forms abide, and the holistic integral Divine Intelligence, or spiritual essence and quintessence, that includes and unifies the individual, collective community, and universal aspects of the indivisible Divine Intelligence. The archetype abides in a dimension of timeless, changeless, permanent being, and gradually unfolds its energy substance or spirit into our individual becoming existence form localized, demarcated, and delimited, in the world of time and space. Our distinctive, relatively unique, particular individual talents, abilities, interests, personal qualities, structural development, and other natural inclinations, proclivities, or predispositions, are mostly derived from our archetypal divine blueprint unfolding into us its inherent energy patterns, which, to some extent (along with other complementary yet also compatible factors such as, environmental influences, happenstance, Darwinian natural selection or experimental trial and error, and personal choice) shape the ongoing development of our individual heart, mind, and body, as well as shaping the cumulative development of our soul or spiritual individuality, and its heart-mind-body containers and instruments, over many successive lifetimes. The genetic predispositions that are inherited from our parents and more distant ancestors correspond to and are balanced by metaphysical or subtler, relatively intangible, influences coming from the archetype, or the timeless permanent being level of our individual spiritual self, or soul.

Similarly, the historical, social, cultural, experiential ethos, and metaphysical development of the collective human species, as well as of particular cohesive ethnic communities, is, to some extent, shaped by a collective spiritual blueprint, prototype, archetype, or pattern existing in the dimension of timeless permanent being. This metaphysical, timeless archetypal pattern unfolding in time and influencing the structural development of individual souls and collective society is somewhat different than the Jungian usage of the term archetype to refer to collective unconscious symbolic, metaphorical, or mythological motifs, but we deem it likely that the development of collective unconscious myth and metaphor is one of many results of the causal influence of the timeless permanent being level of the collective psyche of humanity. Perhaps our view that the universal divine intelligence is gradually growing or advancing in its cumulative level of self-discovery through the gradual cumulative development of the individual and collective psyche of humanity may be compatible and complementary with W.G.F. Hegel's notion that the Absolute Spirit is gradually growing in self-realization through the historical accomplishments and progressively developing ethos of humanity.

Just as an individual tree, flower, or another kind of plant, abiding and growing above ground, is supported, nourished, and directed in its ongoing structural development, or fruition, by the roots of the plant, hidden below ground, similarly, the cumulative structural development of our individual and collective societal heart-mind-body, gradually,

\section{Max Hammer, Barry Hammer \\ The University of Maine, USA}

Correspondence: Barry hammer, The University of Maine, 15 Downeast Terrace, Apt. 2 Orono, Maine (ME) 04473, USA, Tel 207-866-3223, Email mhbj58@gmail.com

Received: October 12, 2015 | Published: October 14, 2015

progressively unfolding in time, is significantly influenced by subtle energies or impartations from a seed-like metaphysical "root" or spiritual core aspect of our life force, abiding in the dimension of timeless permanent being.

This seed-like archetypal blueprint, or prototypal pattern, is a principle of entelechy or directing purposive intelligence that exerts a significant influence on the biological evolution, and corresponding cumulative maturational development of consciousness and subliminal levels of intelligence or psyche, of pre-human, non-human, human, and possibly more advanced post-human species that may arise in the future. We intuitively maintain that the archetypal pattern of a maturely developed and highly evolved individual and collective Divine Self, or Soul, timelessly pre-exists and shapes the cumulative structural development and growing powers of functioning of the individual human and collective humanity or society, in time, by gradually shining its energy patterns, spirit, or life substance into the individual and collective life forms. The individual and collective archetypal self, or life form, inherently, indivisibly united with the universal life substance of the Transpersonal Self, or God, timelessly contains within itself the entelechy, imago, model, or prototype of purposive intention, that guides the cumulative structural development, growing conscious and subliminal intelligence, and expanding powers of functioning, of the individual and collective psyches of humanity.

Our intuition suggests that there may be no final ending to the cumulative development of individual and collective humanity's natural potentials, capabilities, and proclivities, producing possibly endless structural transformations in humanity's heart-mind-body instruments for experiencing, expressing, and epitomizing the limitless range of spiritual being-intelligence, because those potentials are unfolding from a limitless, inexhaustible source, or reservoir, which is the spiritual substance of life, or the Divine Self. Although the spiritual reality of life or intelligence is unfolding its potentials in this delimited world of finite time and space, it is rooted in and unfolding from, a limitless abode of timeless permanent being. 
When individual human beings, social networks, and collective humanity or society become overly identified with exclusive, predetermined self-definitions, self-images, beliefs, and behavioral habits, then that exclusive, conceptually-defined, sense of identity restricts, or to some extent blocks, the ability of the archetype to continue the process of unfolding its potentials into us, or unfolding itself as us, because we are overly attached to what we presume to already know, accomplish, do, and be, and we fear venturing into new possibilities that may not necessarily conform to what the ego or selfgenerated sense of separate narcissistic identity presumes that it can readily understand, predict, and control. The narcissistic ego typically equates rigidity with security through familiarity, predictability, and control, and misinterprets flexibility, involving openness to new possibilities, as a dangerous encounter with mystery, uncertainty, unpredictability, lack of defined self-knowledge or exclusive identity, lack of control, lack of continuity and compatibility with a preselected sense of identity and volitional purpose.

However, the reverse is actually true, that the ego's narcissistic selfpreoccupation and resistive self-will produce a dangerous opposite or antithetical, degenerative, distortion of the naturally regenerative momentum of our life energy force, by restricting or even entirely blocking the archetype from shining its spirit or transformative energy impartations into our overly cluttered, distracted, minds, filled with our own mind chatter or self-generated thought, and our overly cluttered, hearts, filled with narcissistic emotion instead of the pure ecstatic feeling coming from the Divine Self or Soul; and, likewise, the narcissistic ego influences the body senses to be overly inundated by incessant, intense, coarse sensations, impeding our ability to tune into, or non-dualistically commune with, pure spiritual energies arising within and around us.

Lovingly or non-dualistically, empathically, responsively, communing with other individuals and phenomena other than the narcissistic ego, as well as being open to direct, undistorted, unmediated contact with the experiential truth of ourselves, and letting our perception and functioning be guided by the "still small voice" of intuition and core integrity, connects us to the connective relational energy of the spiritual substance of life as love, beyond the ego's selfdefined, self-limited, sense of exclusive, separate identity and resistive self-will. When our individual mind abides in unconditioned or unmodified undifferentiated mind stillness, that is an abode of natural relaxed peace, contentment, openness, and receptivity that enables the archetypal source of greater intelligence and greater powers of functioning to shine or impart its loving energy presence into us without obstruction, as its reflecting mirrors, naturally unified with it in that pure mind stillness. When we are unified with the archetypal root level of our own individual being and of all being, in that way, then it naturally imparts into us ever deeper, higher, grander, more fulfilling, cumulative levels of its warmth of goodness, sweetness, purity, caring, and security, as well as its light of illumined truth understanding, and ecstatic or joyful vitality of life energy substance.

So, our individual spirit becoming form resembles a mirror-like container, receptacle, mold, or pattern into which our archetypal form of Divine Intelligence can unfold itself, i.e., unfold its living energy presence, at ever deeper levels, and thereby know itself. That archetypal radiant energy presence, or divine love flame-light of conscious and subliminal intelligence-vitality of life energy, is what gives our individuality divine or spiritual love-warmth, light, and vitality, indivisibly united together, and endowing us with a limitless range of its intrinsic goodness and grandeur. Just as the individual spirit becoming form is a somewhat grosser or denser container and reflecting mirror-like extension of the archetypal form of Divine Intelligence, the individual soul is an extension of the individual spirit-form, and the individual physical body is an extension of the individual soul form.

Each individual spiritual archetype is like a distinctive idea or form of the universal Divine Intelligence or the connective spiritual life energy substance in which we all abide, and with which we are inherently, indivisibly united. The natural diversity between individual souls, archetypes, or life forms provides the universal Divine Intelligence or the unifying life substance with a limitlessly diverse range of perspectives that serve to accentuate, epitomize, experience, and express, various complementary aspects or viewpoints of itself.

Like many seeds rooted in and growing from the same earth-soil, every individual soul-archetype is grounded in the universal spiritual substance of life and in the collective spiritual form of humanity. The individual and collective soul-archetypes exist or permanently abide within the unifying Divine Intelligence, as ideas within its mind, many splendored aspects within its heart or feeling center, and cells and organs within its body. Just as various crystals or gems, each with different facets, cuts, or patterns, prism and rearrange pure clear light in somewhat different ways, likewise, the pure undifferentiated glory of life energy substance as love gains a limitless range of self-discovery and self-development as each of us naturally reflect, epitomize, experience, and express our individual form of that connective spiritual reality in somewhat different ways, consistent with our archetypal soul blueprint or inherent predispositions.

The one indivisible whole divine intelligence or the universal spiritual energy substance is able to unfold, and, thereby know and cumulatively develop, various aspects, perspectives, potentials, and functions or contributions, of itself through each of its various, somewhat differentiated, particular life forms or individual human beings. When we reflect the pure energy pulse of divine love-goodness without excessive distortion, we thereby serve as individual, relational, and community Divine Ideas or Divine Images of God's, or Life's, Divine Intelligence. When we become overly invested in narcissistic disconnection from others, and/or divorced from the experiential truth of ourselves, that divisive way of functioning distorts the flow of our energy, including impartations coming from the archetype or source level of our being, producing a toxic degenerative energy momentum, instead of the naturally regenerative momentum of pure love-life energy. That divisive, narcissistic way of perceiving and functioning also cuts us off from the Divine Oneness of God or the universal Divine Intelligence. All individual divine ideas or souls naturally abide within an indivisible collective divine idea, image, or form of God's radiant Unity spiritual life energy substance, and are meant to serve as its united, undistorted, reflection, container, house, and temple, including each of our individual variations linked together rather than divisively disconnected from one another.

Male and female soul-mates or twin flames, as well as relative masculine and feminine aspects of each and every individual man or woman, are naturally interrelated, interdependent, indivisible complementary functions or contributions within the same unifying divine idea or spirit/soul archetype. The male principle primarily, but not exclusively, represents the subjective or inner aspect of the Divine Reality, and the female principle primarily, but not exclusively, represents the objective or outer aspect of the Divine Reality Intelligence. Various relative polarities such as, male and female, timeless permanent being and changing becoming, substance and form, unity and diversity, and so on, are relative degrees of one 
another and of the greater all-inclusive reality of love-wholeness in which they both abide, rather than being independent, self-sufficient, self-defining realities in their own right.

\section{Editorial Note:}

Other related insights by Dr. Max Hammer and Dr. Barry Hammer are presented in their two published books, 1) Psychological Healing Through Creative Self-Understanding and Self-Transformation. (ISBN: 978-1-62857-075-5) and 2) Deepening Your Personal Relationships: Developing Emotional Intimacy and Good Communication. (ISBN: 978-1-61897-590-4). The primary author is Dr. Max Hammer, with contributions from secondary authors Dr. Barry J. Hammer and Dr. Alan C. Butler. These books can be purchased from Amazon, Barnes and Noble, or our author/publisher website, http://sbprabooks.com/MaxHammer. The latter website also posts our other articles, and describes our books and us as authors. More articles by Max Hammer and Dr. Barry Hammer are also available at: https://independent.academia.edu/BarryHammer.

\section{Acknowledgments}

None.

\section{Conflicts of interest}

Author declares there are no conflicts of interest.

\section{Funding}

None. 